\title{
DECISIONS
}

\section{A purulent foot ulcer in a man with diabetes mellitus}

\author{
Jeffrey Craig MD, Yasbanoo Moayedi MD, Paul E. Bunce MD
}

A 60-year-old man with poorly controlled type 2 diabetes mellitus and associated neuropathy presents to his family doctor with a wound on the plantar aspect of his left foot. He has no history of foot ulcers. The ulcerating wound, which has been present for 6 weeks, has recently become purulent and foul smelling. The physician feels underlying bone when probing the ulcer with a sterile instrument. A superficial swab of the wound is performed, from which methicillin-susceptible Staphylococcus aureus and Pseudomonas aeruginosa are isolated. The physician considers the relevant components of the management of this patient's condition.

\section{Is this patient's foot ulcer infected?}

Not all foot ulcers in patients with diabetes are infected. However, this patient's history and physical examination are suggestive of a mild to moderate diabetic foot infection (Table 1). At least 2 signs of inflammation (i.e., erythema, warmth, pain, induration or purulence) should be present to diagnose a diabetic foot infection. ${ }^{1}$ Factors shown to increase the risk of a diabetic foot infection include a history of diabetic neuropathy, recurrent ulcers or ulceration for more than 30 days, traumatic wound, peripheral vascular disease in the affected limb (e.g., ankle brachial index < 0.9) and renal impairment. ${ }^{1,2}$

\section{Should another wound culture be done before starting antimicrobial therapy, and if so, how?}

This patient is hemodynamically stable with a new diagnosis of a diabetic foot infection. A proper wound culture should be done before antibiotic therapy is started. Swabs of the superficial surface of the ulcer are inadequate and are generally discouraged. Such samples are prone to contamination with commensal and colonizing organisms (such as Pseudomonas species and methicillin-resistant $S$. aureus) and will often fail to detect the true deep-tissue pathogens. Recent clinical practice guidelines from the Infectious Diseases Society of America recommend culturing deep tissue from biopsy or curettage of the ulcer base after the cleaning and débridement of the wound. ${ }^{1}$ Clinicians uncomfortable performing débridement should consider referral to a specialist. Purulent collections can be aspirated and provide acceptable samples for culture. ${ }^{1}$

In some cases, empiric therapy may be started before obtaining culture results and should be directed at typical skin organisms such as S. aureus and streptococci. ${ }^{1}$ In such cases, careful follow-up is needed to ensure adequate response. Antibiotic agents should be changed to the narrowest spectrum of effective therapy once the culture results are available or if risk factors for other organisms are present (Table 1). ${ }^{1}$ For this patient, given the acuity of the infection and lack of recent antibiotic exposure, empiric treatment with cloxacillin given intravenously was started pending culture results.

\section{After deep tissue cultures are obtained, what further evaluation is needed?}

The duration of recommended antimicrobial therapy is determined by the extent of the infection, specifically whether there is underlying osteomyelitis. In the absence of complication (e.g., abscess or osteomyelitis), treatment for 710 days is usually sufficient, although longer courses may be recommended for severe infections. ${ }^{1}$ In cases of osteomyelitis, treatment is typically for 6 weeks. The ability to probe to underlying bone with a narrow, hard object is highly suggestive of infection with underlying osteomyelitis (positive likelihood ratio 6.4, 95\% confidence interval [CI] 3.6-11). ${ }^{3}$ Despite their frequent use in these settings, both erythrocyte sedimentation rate and C-reactive protein level lack sufficient evidence to justify their use in diagnosing osteomyelitis..$^{1,3}$ Plain radiographs, although insensitive for osteomyelitis (sensitivity 0.54, 95\% CI 0.44-0.63), are appropriate firstline imaging tests and may also show underlying soft-tissue gas or foreign bodies. ${ }^{1,4}$ Magnetic resonance imaging (MRI) should be done if radiographs appear normal but suspicion of osteomyelitis remains high, or if there is suspicion of soft-tissue abscess. Combination radionuclide bone scan and labelled leukocyte
Competing interests: None declared.

This article has been peer reviewed.

Correspondence to:

Paul E. Bunce,

paul.bunce@uhn.ca

CMAJ 2013. DOI:10.1503

/cmaj.121527 
Table 1: Classification of severity and microbiological considerations in diabetic foot infection ${ }^{1,2}$

\begin{tabular}{|c|c|c|}
\hline Severity & Characteristics & Common causative pathogens \\
\hline $\begin{array}{l}\text { Local infection involving epidermis and } \\
\text { subcutaneous tissue }\end{array}$ & $\begin{array}{l}\text { Local signs of inflammation in the } \\
\text { absence of systemic signs and symptoms }\end{array}$ & Aerobic gram-positive cocci \\
\hline \multicolumn{3}{|l|}{ Moderate } \\
\hline $\begin{array}{l}\text { Infection involving tissue deeper than } \\
\text { epidermis and subcutaneous tissue }\end{array}$ & $\begin{array}{l}\text { Local signs of inflammation with } \\
\text { erythema }>2 \mathrm{~cm} \text { in the absence of } \\
\text { systemic signs }\end{array}$ & $\begin{array}{l}\text { Acute, less extensive: aerobic gram- } \\
\text { positive cocci } \\
\text { Chronic, more extensive: gram-positive } \\
\text { and gram-negative organisms, anaerobes }\end{array}$ \\
\hline \multicolumn{3}{|l|}{ Severe } \\
\hline $\begin{array}{l}\text { Local infection with signs of systemic } \\
\text { inflammatory response syndrome* }\end{array}$ & $\begin{array}{l}\text { Hemodynamic compromise, metabolic } \\
\text { disturbances (severe hyperglycemia, new } \\
\text { onset renal insufficiency) }\end{array}$ & $\begin{array}{l}\text { Gram-positive organisms (including } \\
\text { MRSA), gram-negative organisms, } \\
\text { anaerobes }\end{array}$ \\
\hline & $\begin{array}{l}\text { Frequent exposure to water, high local } \\
\text { prevalence, warm climate }\end{array}$ & Pseudomonas aeruginosa \\
\hline \multicolumn{3}{|c|}{$\begin{array}{l}\text { Note: MRSA = methicillin-resistant Staphylococcus aureus. } \\
\text { *The presence of more than } 2 \text { of the following signs and symptoms: temperature higher than } 38^{\circ} \mathrm{C} \text { or lower than } 36^{\circ} \mathrm{C} \text {; heart rate faster than } 90 \text { beats } / \mathrm{min} \text {; } \\
\text { respiratory rate faster than } 20 \text { breaths } / \mathrm{min} \text {; partial pressure of carbon dioxide less than } 32 \mathrm{~mm} \mathrm{Hg} \text { leukocyte count greater than } 12 \text { or less than } 4 \text { cells } / \mathrm{mL} \text {, or more } \\
\text { than } 10 \% \text { bands. }\end{array}$} \\
\hline
\end{tabular}

scan can be considered if MRI is contraindicated or unavailable. ${ }^{1}$ Arterial vascular studies may be done to determine whether arterial revascularization is indicated. ${ }^{1}$ Admission to hospital should be considered for all moderate to severe diabetic foot infections to allow close monitoring and administration of antibiotics intravenously.

\section{After starting treatment, what additional therapies can assist in wound healing?}

This patient should be informed that his wound may persist after he has finished the course of antibiotics. Frequent reassessment with débridements will assist in eliminating any potential pathogenic reservoir and promote the formation of granulation tissue. ${ }^{1}$ Pressure off-loading, improved glycemic control and ensuring adequate vascular supply to the limb are also important in wound healing. ${ }^{1}$ Adjunctive therapies such as hyperbaric oxygen, maggots and vacuumassisted closure devices lack sufficient data at this time to be recommended as part of routine therapy. ${ }^{1}$ Multidisciplinary care by physicians, wound care experts and chiropodists to detect any new ulcers and prevent future infections has been shown to substantially reduce the rate of subsequent amputations, and its importance cannot be overemphasized. ${ }^{5}$

\section{References}

1. Lipsky BA, Berendt AR, Cornia PB, et al. 2012 Infectious Diseases Society of America clinical practice guideline for the diagnosis and treatment of diabetic foot infections. Clin Infect Dis 2012; 54:e132-73.

2. Williams DT, Hilton JR, Harding KG. Diagnosing foot infection in diabetes. Clin Infect Dis 2004;39:S83-6.

3. Butalia S, Palda VA, Sargeant RJ, et al. Does this patient with diabetes have osteomyelitis of the lower extremity? JAMA 2008;299: 806-13.

4. Dinh MT, Abad CL, Safdar N. Diagnostic accuracy of the physical examination and imaging tests for osteomyelitis underlying diabetic foot ulcers: meta-analysis. Clin Infect Dis 2008;47:519-27.

5. Krishnan S, Nash F, Baker N, et al. Reduction in diabetic amputations over 11 years in a defined UK population: benefits of multidisciplinary team work and continuous prospective audit. Diabetes Care 2008;31:99-101.

Affiliations: From the Department of Medicine (Craig, Moayedi, Bunce), University of Toronto; and the Division of Infectious Diseases (Bunce), University Health Network, Toronto, Ont.

Contributors: All of the authors contributed to the preparation of this manuscript. All of the authors approved the final version of the manuscript submitted for publication. 